\title{
Virtual Reality Driving Simulation for Measuring Driver Behavior and Characteristics
}

\author{
Seyyed Meisam Taheri*, Kojiro Matsushita, Minoru Sasaki \\ Department of Human and Information Systems Engineering, Gifu University, Gifu, Japan \\ Email: *s3812005@edu.gifu-u.ac.jp, kojirom@gifu-u.ac.jp, sasaki@gifu-u.ac.jp
}

How to cite this paper: Taheri, S.M., Matsushita, K. and Sasaki, M. (2017) Virtual Reality Driving Simulation for Measuring Driver Behavior and Characteristics. Journal of Transportation Technologies, 7, 123-132. https://doi.org/10.4236/jtts.2017.72009

Received: January 20, 2017

Accepted: April 9, 2017

Published: April 12, 2017

Copyright $\odot 2017$ by authors and Scientific Research Publishing Inc. This work is licensed under the Creative Commons Attribution International License (CC BY 4.0).

http://creativecommons.org/licenses/by/4.0/

\section{(c) (i) Open Access}

\begin{abstract}
This article provides new insights regarding driver behavior, techniques and adaptability. This study has been done because: 1 ) driving a vehicle is critical and one of the most common daily tasks; 2) simulators are used for the purpose of training and researching driver behavior and characteristics; 3 ) the article addresses driver experience by involving new virtual reality technologies. A simulator has been used to assist novice drivers to learn how to drive in a very safe environment, and researching and collecting data for researchers has become easier due to this secure and user-friendly environment. The theoretical framework of this driving simulation has been designed by using the Unity3D game engine (5.4.f3 version) and was programmed with the C\# programming language. To make the driving environment more realistic we, in addition, utilized the HTC Vive Virtual reality headset which is powered by Steamvr. We used Unity Game Engine to design our scenarios and maps because by doing this we are able to be more flexible with designing. In this study, we asked 10 people ranging from ages 19 - 37 to participate in this experiment. Four Japanese divers and six non-Japanese drivers engaged in this study, some of which do not have a driver's license in Japan. A few Japanese drivers have a license and car, while others have a license but no car. In order to analyze the results of this experiment we are used MatlabR2016b to analyze the gathered data. The result of this research indicates that individual's behavior and characteristics such as controlling the speed, remaining calm and relaxed when driving, driving at appropriate speeds depending on changes in road structures and etc. can affect their driving performance.
\end{abstract}

\section{Keywords}

Driver, Behavior, Game, Driving, Unity3D, Virtual Reality, Simulation, HTC

\section{Introduction}

Driving simulators, aside from being research tools, have grown to be an impor- 
tant tool in the area of road safety. They are providing an environment for a driver which is safer because there are not any physical obstacles or harm. This gives the administrator of a simulation the ability to manipulate and apply the situations which are not possible on-road in real time [1]. In recent times, driving simulations have been helping researchers as a useful research tool [2] and they have shown many advantages which can be programmed to easily be like real, on-road driving [3] [4]. This allows researchers to apply and experiment with different factors based on driver response and a considerable amount of different conditions which are quite impossible otherwise [2]. These include investigating driving in conditions such as: the effects of alcohol, drugs and fatigue on driving behavior [5]. As well as, the performance of older drivers [6] or driving performance is in different environmental conditions [7].

A well designed simulator can assess the act of drivers, and also can deliver valuable road safety information. A driving simulator applies an experimental design that is adaptable and easy to repeat. It offers the ability to modify driving scenarios at any time and expose drivers to dangerous situations in a methodical manner. Simulator studies have recognized to be a reliable tool which incorporates with intuitive input, cognitive processing and behavioral output [5]. Inclusively, simulation based driving may not be exactly the same on-road driving behaviors [8]. Therefore, the aim of this study is to compare the driving performance using a Game engine-based driving simulator (Unity3D game engine driving Game) as well as, finding driving violations and driver characteristics such as driving too fast, braking to hard or softly and staying on-road or going off-road. Participants were instructed to drive on a specific map. The simulation was designed in unity3 $\mathrm{D}$ game engine and programmed by $\mathrm{C} \#$ language. A questionnaire was also given to participants, asking them about their personal information and their driving experience in Japan, and in their home countries. Participants who contributed in this study were ages 19 to 35 years old including 6 non-Japanese and 4 Japanese drivers. Nine of them were male and one was female.

\subsection{Study Scheme}

A study was commenced to observe driver adaptively to a 3d Driving Simulation by measuring driver behavioral responses in the simulator.

\subsection{Participants in This Study}

A convenience sample of drivers ages 19 to 35, some of which held a driver license and some of which did not, in Japan, were asked to assist us in this study. 4 Japanese volunteers who have already received their drivers license and 6 nonJapanese Gifu residents. Three of these students have a driver's license in their home country but not in Japan.

\subsection{Data Collection}

All participants volunteered to participate in this study, as well as filled out a 
questionnaire afterwards regarding their experience while driving a 3D simulated driving game. As the participants drove, an instructor was beside them to guide them and help them if they would have some sort of issue during the practice. Some participants were new to the $3 \mathrm{D}$ virtual reality world, and could not finish their task due to their dizziness and worsening eyesight irritation during the simulation. The data was saved for later review and study for future work. All the Data was saved individually in a CSV file (Figure 1), with the same conditions using a capture card (AverMedia C875) all throughout all steps of the experiment were recorded.

\subsection{Driving Simulator Evaluation}

The map and route was developed by Unity3D game engine and programmed by C\# programming language. The map is too big so finishing each Lap took drivers approximately 1.5 minutes to finish. The simulator driving took about fifteen minutes on average to complete. Drivers practiced the map and memorized it before the experiment commenced, and an assessor was next to them to teach them about the map and how they could improve their driving skills. The results of each participant were shown to them after finishing their tasks required for data collection.

\subsection{Outcome Driving Performance Measures}

As Figure 1 illustrates, in this study we measured driver tendencies (head movements), speed control (accelerating and braking), position of the vehicle, control of the vehicle (steering wheel rotation and so on). The specific tasks examined included: adjusting speed when approaching the bridge, turning and passing

\begin{tabular}{|c|c|c|c|c|c|c|c|c|c|c|c|c|c|c|c|c|c|c|}
\hline \multirow{4}{*}{$\begin{array}{c}\text { The Columns are } \\
\text { representing }\end{array}$} & \multirow{2}{*}{$\begin{array}{l}\text { A1 } \\
\text { L }\end{array}$} & \multirow{2}{*}{\multicolumn{2}{|c|}{$\begin{array}{c}\Delta \times \vee f \\
A\end{array}$}} & \multicolumn{2}{|c|}{\begin{tabular}{l|l}
$f x$ & 306.8803
\end{tabular}} & \multirow[b]{2}{*}{ E } & \multirow[b]{2}{*}{$\mathrm{F}$} & \multirow[b]{2}{*}{ G } & \multirow[b]{2}{*}{ H } & & \multirow[b]{2}{*}{ J } & \multirow[b]{2}{*}{ k } & \multirow[b]{2}{*}{ L } & \multirow[b]{2}{*}{ M } & & \multirow[b]{2}{*}{0} & & \multirow[b]{2}{*}{ Q } \\
\hline & & & & c & D & & & & & & & & & & & & & \\
\hline & 1 & 306.8803 & 1.759032 & 205.8389 & 323.66333 & 170.854279 & 358.273926 & 0.02 & 20.0000057 & 7180.487213 & 1.28E-07 & 307.03 & 0.7999998 & 205.56 & $.854 \mathrm{E}-07$ & 180.4872 & 1.10E-07 & 0 \\
\hline & 2 & 306.8786 & 1.756563 & 205.8392 & 323.630981 & 170.933853 & 358.139282 & 0.02 & 19.9861546 & 6180.446121 & 359.880493 & 307.0302 & 0.7978976 & 205.56 & 359.9862 & 180.487 & 359.8877 & 0 \\
\hline Camera Position & 3 & 306.8663 & 1.744376 & 205.8404 & 323.510559 & 171.621643 & 357.425537 & 0.07074369 & 19.9425354 & 4180.200302 & 355.367645 & 307.0295 & 0.7876632 & 205.56 & 359.9447 & 180.4873 & 359.2124 & 0 \\
\hline A: Head X & 4 & 306.8603 & 1.739482 & 205.8234 & 326.098633 & 173.896057 & 1.0911268 & 0.01568678 & 19.9364738 & 8180.139694 & 355.190765 & 307.0292 & 0.7848303 & 205.56 & 359.9401 & 180.4875 & 359.0484 & 0 \\
\hline B: Head Y & 5 & 306.8575 & 1.736549 & 205.8232 & 326.12381 & 174.039474 & 0.81621981 & 0.01325964 & 19.9339542 & $2 \quad 180.09227$ & 355.051971 & 307.0289 & 0.7824242 & 205.56 & 359.9387 & 180.4877 & 358.9189 & 4 \\
\hline \multirow[t]{2}{*}{ C: Head Z } & 6 & 306.8549 & 1.733597 & 205.8231 & 326.133942 & 174.113937 & 0.67549801 & 0.01441751 & 19.9355526 & 6180.048248 & 354.922607 & 307.0286 & 0.7798491 & 205.56 & 359.9403 & 180.4879 & 358.7919 & 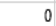 \\
\hline & 7 & 306.8526 & 1.730855 & 205.8228 & 326.211731 & 174.230667 & 0.53141373 & 0.01369065 & 19.9393787 & 180.01059 & 354.811676 & 307.0283 & 0.7775004 & 205.56 & 359.9452 & 180.4881 & 358.6893 & 0 \\
\hline camera angle & 8 & 306.8499 & 1.726684 & 205.8224 & 326.207947 & 174.373917 & 0.30912763 & 0.0227554 & 19.9531612 & 179.963226 & 354.671173 & 307.0278 & 0.7738887 & 205.56 & 359.9601 & 180.4882 & 358.5584 & 0 \\
\hline D: Head Roll & 9 & 306.8483 & 1.72344 & 205.8219 & 326.203186 & 174.427322 & 0.18766783 & 0.02249583 & 19.9752159 & 179.935425 & 354.587738 & 307.0275 & 0.7708055 & 205.5601 & 359.9828 & 180.4882 & 358.4817 & 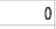 \\
\hline E: Head Pith & 10 & 306.8478 & 1.720885 & 205.821 & 326.192322 & 174.443054 & 0.12526822 & 0.0223783 & 20.0042458 & 179.925751 & 354.55719 & 307.0273 & 0.768316 & 205.5601 & 0.01189535 & 180.488 & 358.4552 & 0 \\
\hline F: Head Yaw & 11 & 306.8477 & 1.719263 & 205.8202 & 326.228149 & 174.476425 & 0.09739455 & 0.02209062 & 20.0379486 & 179.931458 & 354.571564 & 307.0271 & 0.7664759 & 205.5601 & 0.04527458 & 180.4878 & 358.4713 & 0 \\
\hline Time & 12 & 306.8486 & 1.718062 & 205.8193 & 326.294373 & 174.490433 & 0.11875345 & 0.02255766 & 20.0752373 & 179.949554 & 354.622131 & 307.027 & 0.7652444 & 205.5601 & 0.08190536 & 180.4876 & 358.5215 & 0 \\
\hline \multirow[t]{2}{*}{ G: Delta time } & 13 & 306.8495 & 1.717856 & 205.8186 & 326.313843 & 174.427094 & 0.22016367 & 0.01919976 & 20.1070843 & 179.971313 & 354.683319 & 307.027 & 0.7646853 & 205.56 & 0.1133252 & 180.4875 & 358.5823 & 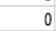 \\
\hline & 14 & 306.8503 & 1.718005 & 205.8183 & 326.362579 & 174.388031 & 0.31338641 & 0.01372028 & 20.1294689 & $\begin{array}{l}979.9897 \\
\end{array}$ & 354.736053 & 307.027 & 0.7645634 & 205.5601 & 0.1349734 & 180.4874 & 358.6324 & 0 \\
\hline Steering wheel Angle & 15 & 306.8511 & 1.718244 & 205.818 & 326.401459 & 174.352493 & 0.39119941 & 0.01247094 & 20.1487198 & 380.00705 & 354.78595 & 307.0271 & 0.7646213 & 205.56 & 0.1536217 & 180.4874 & 358.6797 & 0 \\
\hline $\mathrm{H}$ : Steering wheel Roll & 16 & 306.8517 & 1.718808 & 205.8179 & 326.458984 & 174.349274 & 0.44149286 & 0.01256113 & 20.1667614 & 180.024658 & 354.836884 & 307.0272 & 0.7648311 & 205.56 & 0.1710406 & 180.4875 & 358.7276 & 0 \\
\hline I: Steering wheel Pitch & 17 & 306.8529 & 1.719621 & 205.8177 & 326.545135 & 174.373489 & 0.48265728 & 0.01767883 & 20.1883049 & 180.047836 & 354.905029 & 307.0273 & 0.7653546 & 205.56 & 0.1926235 & 180.4876 & 358.7925 & 0 \\
\hline \multirow[t]{2}{*}{ J: Steering wheel Yaw } & 18 & 306.8534 & 1.720515 & 205.8183 & 326.755524 & 174.633957 & 0.3982096 & 0.01316076 & 20.2022285 & 180.064209 & 354.953369 & 307.0273 & 0.7658992 & 205.56 & 0.2059342 & 180.4877 & 358.8369 & 0 \\
\hline & 19 & 306.8542 & 1.721335 & 205.8186 & 326.908752 & 174.799362 & 0.40017056 & 0.01285673 & 20.2133198 & 180.078598 & 354.995789 & 307.0274 & 0.7665289 & 205.56 & 0.2165259 & 180.4878 & 358.8759 & 0 \\
\hline car Position & 20 & 306.855 & 1.722229 & 205.8199 & 327.146881 & 175.205139 & 0.37565678 & 0.01207698 & 20.2212486 & 180.090347 & 355.030487 & 307.0275 & 0.7671926 & 205.56 & 0.2241281 & 180.4879 & 358.9079 & 0 \\
\hline K: car Position X & 21 & 306.8564 & 1.723709 & 205.8215 & 327.329956 & 175.489777 & 0.50108641 & 0.020491 & 20.2285881 & 180.105789 & 355.076233 & 307.0276 & 0.768435 & 205.56 & 0.2314827 & 180.488 & 358.9507 & 0 \\
\hline L: car Position Y & 22 & 306.8579 & 1.725542 & 205.8238 & 327.373047 & 175.568588 & 0.69534945 & 0.02220304 & 20.2287521 & 180.116486 & 355.107849 & 307.0277 & 0.7698692 & 205.56 & 0.2315755 & 180.4881 & 358.9801 & 0 \\
\hline \multirow[t]{2}{*}{ M: car Position Z } & 23 & 306.8591 & 1.727549 & 205.8259 & 327.265076 & 175.447128 & 0.82844687 & 0.02221045 & 20.2208729 & 180.121048 & 355.121277 & 307.0278 & 0.7713106 & 205.56 & 0.2237626 & 180.4882 & 358.9927 & 0 \\
\hline & 24 & 306.8597 & 1.729013 & 205.8269 & 327.18161 & 175.234406 & 0.83453423 & 0.0189062 & 20.2083664 & + 180.120804 & 355.120422 & 307.0279 & 0.7724878 & 205.56 & 0.2115287 & 180.4882 & 358.9921 & 0 \\
\hline Car Angle & 25 & 306.8601 & 1.729813 & 205.8275 & 327.069458 & 175.139023 & 0.8448329 & 0.01335749 & 20.1968174 & 180.118546 & 355.11377 & 307.0279 & 0.7732662 & 205.56 & 0.2000119 & 180.4881 & 358.9861 & 0 \\
\hline $\mathrm{N}$ : Car Roll & 26 & 306.8606 & 1.730573 & 205.828 & 326.991669 & 175.087906 & 0.86758733 & 0.01262117 & 20.1840782 & 180.11528 & 355.104034 & 307.028 & 0.7739525 & 205.56 & 0.1873911 & 180.4881 & 358.9772 & 0 \\
\hline O: Car Pitch & 27 & 306.861 & 1.731238 & 205.8287 & 327.007233 & 175.10379 & 0.80793047 & 0.01476523 & 20.1673222 & 180.110321 & 355.089325 & 307.028 & 0.7746865 & 205.56 & 0.1708512 & 180.4881 & 358.964 & 0 \\
\hline \multirow[t]{2}{*}{ P: Car Yaw } & 28 & 306.8612 & 1.73167 & 205.8291 & 327.072662 & 175.212921 & 0.73205966 & 0.01231509 & 20.15205 & 180.10556 & 355.075134 & 307.0279 & 0.7752325 & 205.56 & 0.1558319 & 180.4881 & 358.9511 & 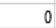 \\
\hline & 29 & 306.8614 & 1.731894 & 205.8298 & 327.2677 & 175.334412 & 0.70228279 & 0.0129763 & 20.1354408 & 180.10054 & 355.059753 & 307.0279 & 0.7757344 & 205.56 & 0.139105 & 180.488 & 358.9364 & 0 \\
\hline Trigger Data & 30 & 306.8614 & 1.731961 & 205.8305 & 327.654663 & 175.460861 & 0.63562375 & 0.01296301 & 20.1179562 & 180.095016 & 355.043213 & 307.0279 & 0.7761617 & 205.56 & 0.1218645 & 180.488 & 358.9213 & 0 \\
\hline \multirow[t]{2}{*}{ Q: Trigger } & 31 & 306.8618 & 1.731372 & 205.8325 & 328.757599 & 176.075729 & 0.27892935 & 0.01354144 & 20.099432 & 180.089325 & 355.026123 & 307.0278 & 0.7765299 & 205.5601 & 0.103649 & 180.488 & 358.9058 & 0 \\
\hline & & & & & & & & & & & & & & & & & & \\
\hline
\end{tabular}

Figure 1. A sample of the gathered data in a CSV file. 
intersections and keeping right and driving between right lanes. It was also vital to check their level of fatigue while driving which will be discussed in the analyzing section in greater details.

\section{The Experiment Setup}

The experiment setup in this study is divided into two parts: hardware and software setup. As Figure 2 presents, a high spec desktop computer with an Intel Core i7 CPU 4GHz, a 16GB RAM and a GeForce GTX 8GB graphics card was provided for this study. For some parts of this research we used a normal monitor and for the virtual reality part of this research we used HTC vive Virtual reality headset. There are some external measurement devices which we have not used yet in this current research, but they will be used for future works. A Thrust master T150 steering wheel used for driving in simulation (Figure 3), and a Aver Media C875 recording device was used to record the simulation during the data collection, Figure 2 presents the hardware flowchart and connections in this setup.

Some software and applications are being used in this study in order to design, develop and analyze the data. The simulation is running in Unity3D game engine, a 3D flexible environment which gives us the freedom to design and manipulate the simulation at anytime during the research. The codes are programmed by using C\# language inside the Monodevelop IDE. Microsoft Excel and Matlab are being used to record and analyze the gathered data as you can see in the Figure 1.

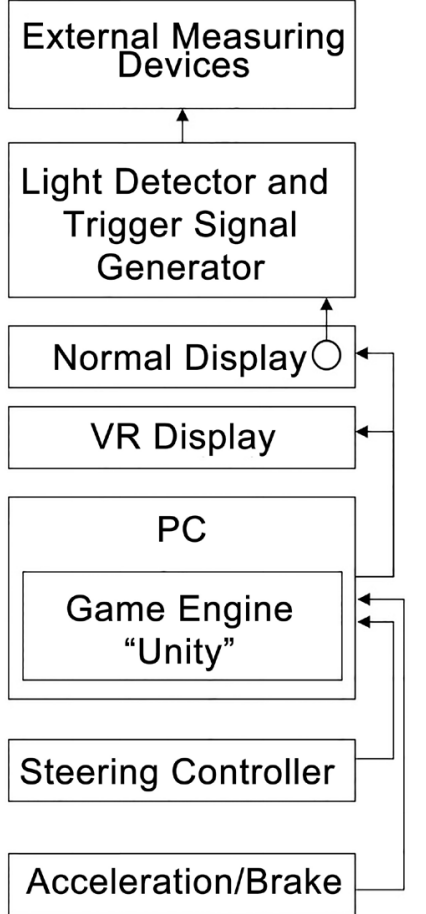

Figure 2. The hardware setup. 


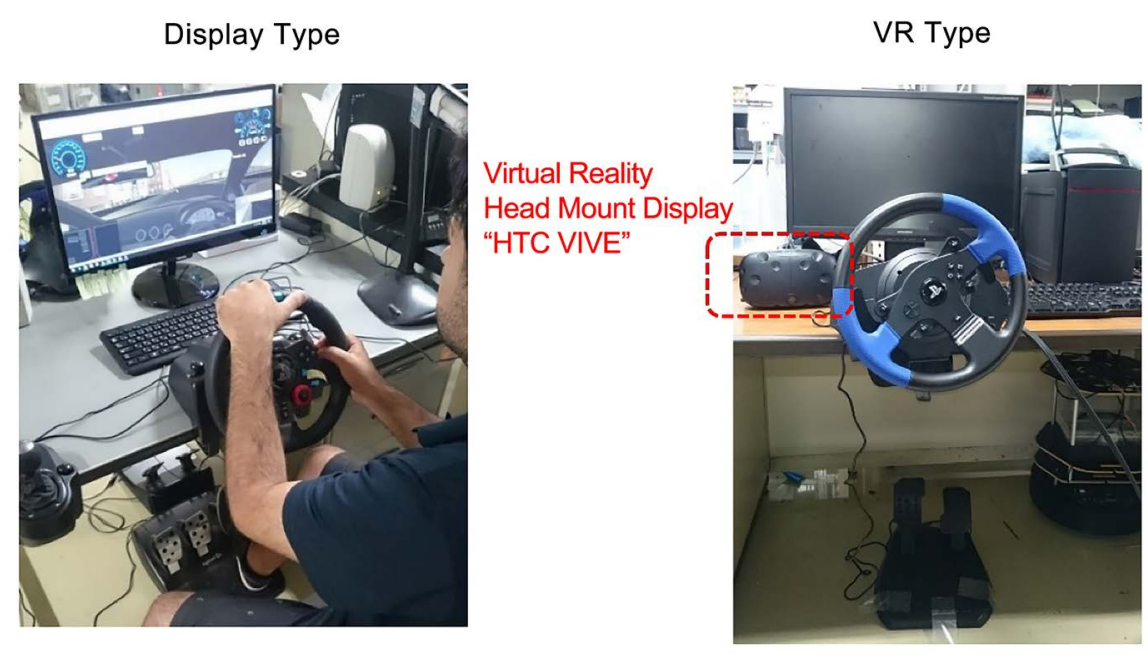

Figure 3. Experiment setup.

\section{Data Analysis}

The following results belong to a 26 years old Malaysian participant. He has a valid Malaysian driving license but not a Japanese one. He received his driving license 5 years ago. He doesn't own a car and he is not interested in driving cars, however he likes playing computer driving games, which may affect the results of this experiment. He drove cars about one year and he considers himself a cautious driver. We asked him "How difficult was it for you to adjust to the simulation?". He answered that it was neither very easy nor very difficult for him to drive the car in the simulator. Furthermore, he mentioned that around Lap 6th he felt tired of driving. This made him try some different things like drive faster. By pushing the accelerator and going faster he was trying to experiment with the physics of the car and observe the consequences of his actions. In this study the results of his choices have been studied.

The following are his point of views of the simulator:

\section{Pros:}

1) The physics for the driving simulation (i.e. car handling, momentum, tire friction etc.) are great. It does feel like driving a real car.

2) The application of VR for the simulation gives a more realistic driving perspective as opposed to the conventional method (monitor screen).

\section{Cons:}

1) The Simulation track landscape or the world is too simple in his opinion. In a real world car driving scenario, there are many aspects to consider, such as human presence and obstacles.

2) Car steering for the simulation differs from real world car steering.

3) Simulation graphic interface might be too low.

The following figure illustrates the time which this driver took to drive the car in the simulation for each Lap (from Lap 2 to 9). Units are measured in seconds. Overall, the spent time for Laps 5, 6 and 7 is lower than other Laps. The time which was spent for those Laps requires a higher speed for a driver to finish those 
Laps. Other figures and charts will relatively show that higher speeds affected the performance of the driver negatively (Figure 4, Figure 5). Figure 4 and Figure 5 illustrate driver could not control the car on the bridge due to the high speed.

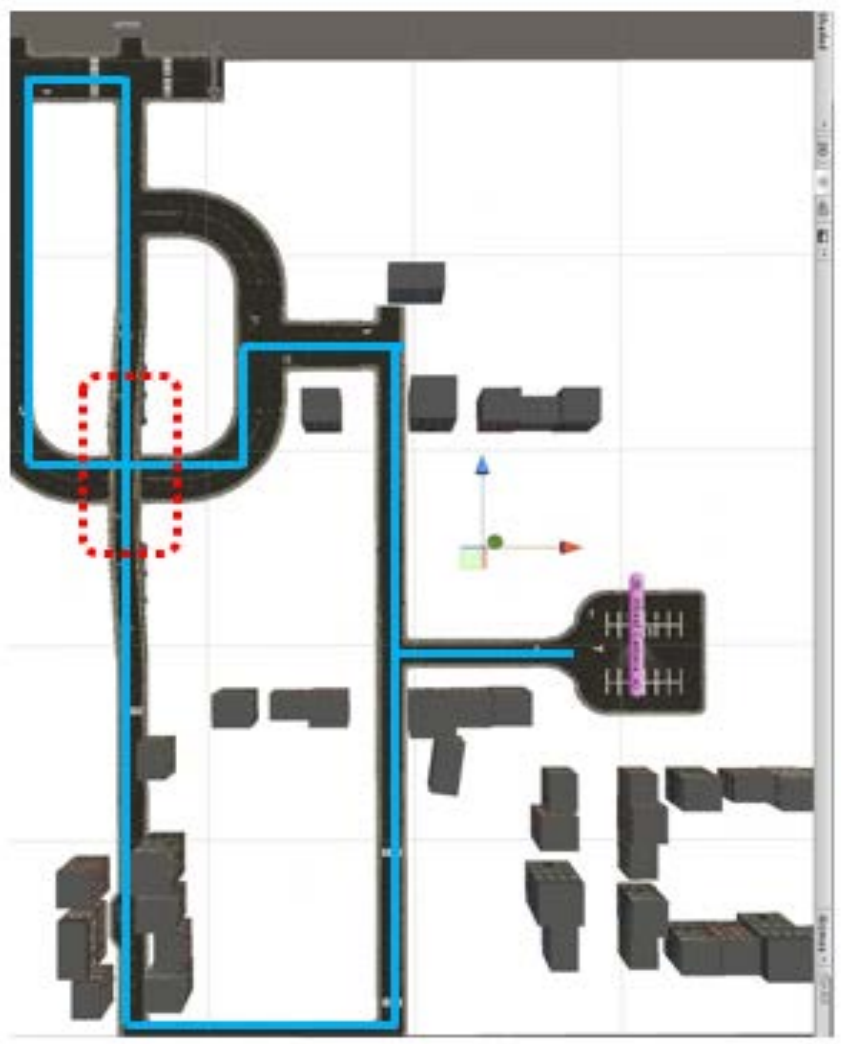

Figure 4. Bird's eye view of the map with the bridge marked.

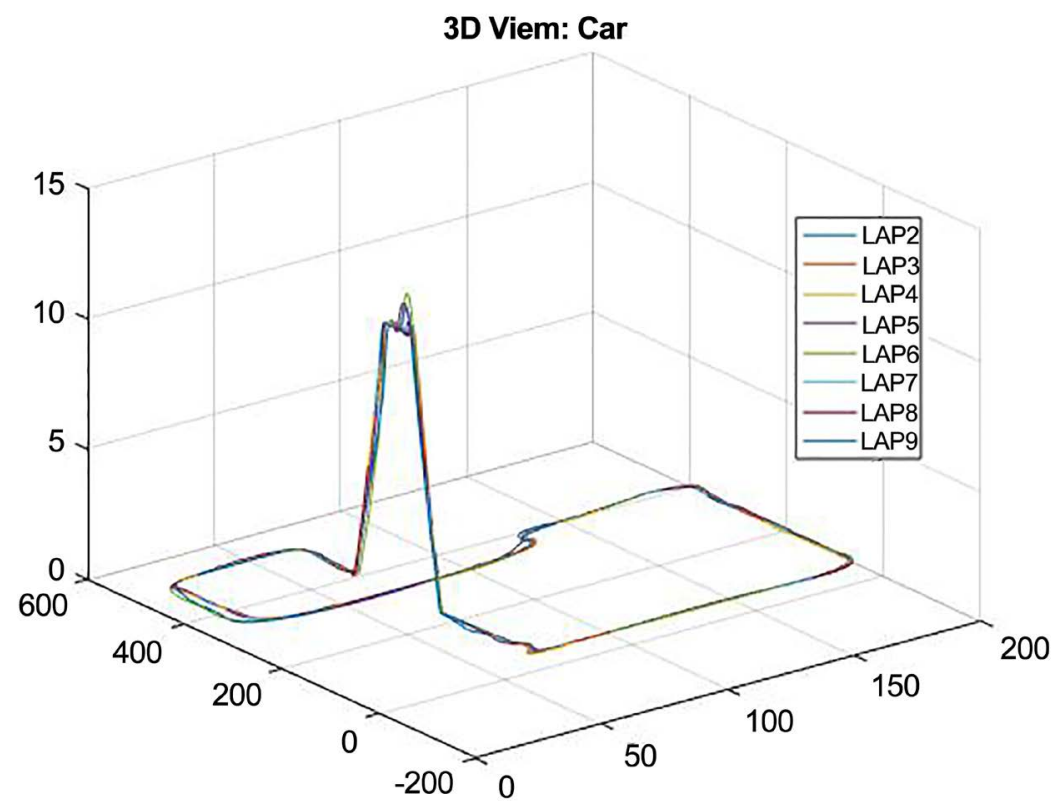

Figure 5. 3D view of car movements. 
The following graph shows the 2D view of the driver's performance between Lap 2 to 10. In this graph, Purple, green and light blue are representing Lap 5, 6 and 7 respectively. As we mentioned in the fig $\mathrm{x}$, the driver had a higher speed in those Laps. The average time of all Laps is 77.14 seconds which is higher than the time of 5, 6, and 7th Laps which are 66.96, 66.52 and 72.28 respectively, and besides that, the average time of those three Laps is 66.92 seconds. This $2 \mathrm{D}$ view shows that the driver lost his control and he could not drive along the inside of the road. On the displacements of the coordinates of the car in Figure 1, it is obvious that driver was not able to control the car properly. In the beginning of the course, the driver was driving slower compared to other Laps, where he was more careful and adapting to the system. Gradually, the driver decided to experience driving with a higher speed. It was evident that driver felt considerably tired while driving slow as it was uninteresting. After noticing that he was not doing well for almost 3 Laps he decided to drive slowly once more and control the car perfectly.

Figure 6 shows a bird's eye view of the driver performance from Laps 2 to 9. Different colors representing the Laps show that on most Laps the driver was performing the same and was driving within the road and cautiously. The Axis of this graph represents the coordinates of the car in $\mathrm{X}$-axis and $\mathrm{Y}$-axis. Sudden changes in Laps 5th, 6th and 7th are easily seen in this graph, as Figure 7 which represented these changes as well.

Figure 8 details the amount of pressure applied to the brake by the driver. The significant thing about the changes in this graph is: in 3 specific Laps the driver had a higher speed when compared with the other Laps, which resulted in him applying more pressure on the brakes when compared to other Laps. The graphs for Laps 5, 6 and 7 illustrate that the driver was breaking more suddenly, which contrasts the data in the graphs for the rest of the Laps. After the period of time

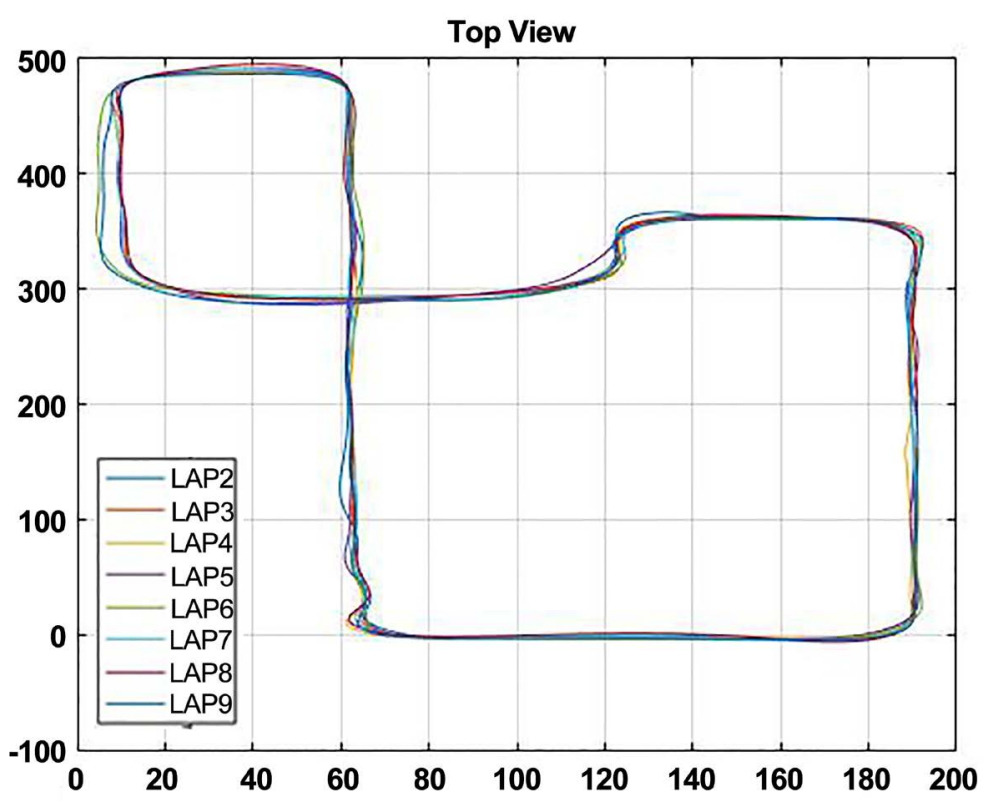

Figure 6. Bird's eye view of the result of the car displacement. 


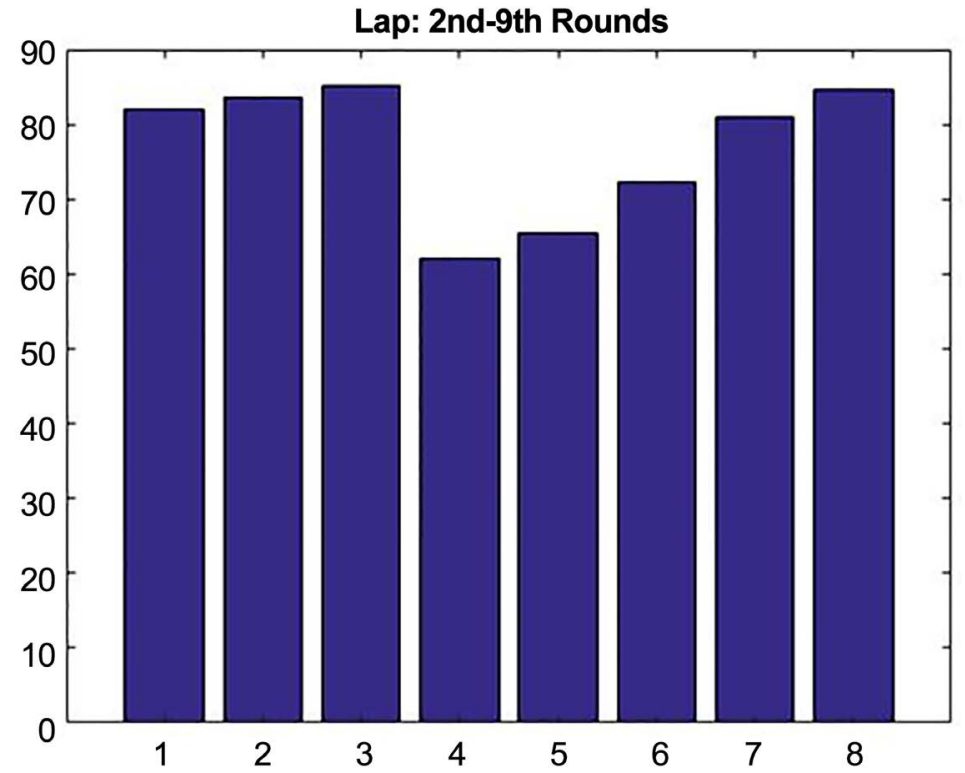

Figure 7. Time of each Lap.

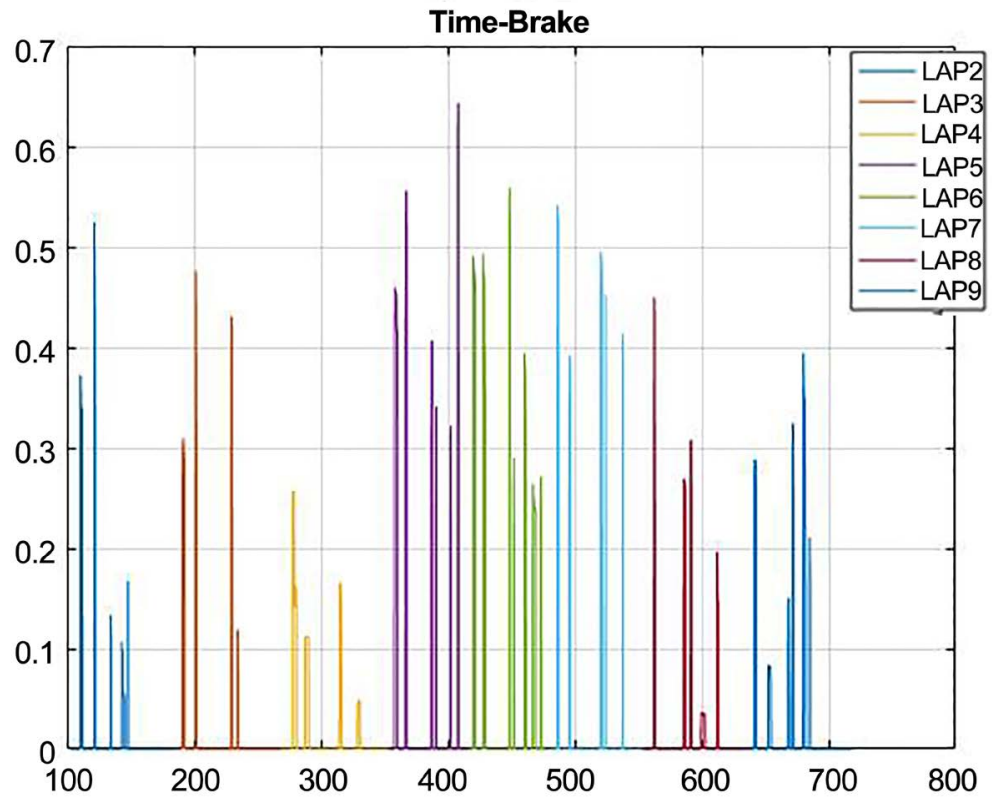

Figure 8. Brake data of each Lap.

taken by Laps $5-7$, the driver seemed to pay attention more to his driving and behavior and tendencies went back to normal. Figure 9 presents the acceleration data, similarly, the accelerating results show that the acceleration amount increased beginning at Lap 5 and decreasing after Lap 7. Furthermore, according to Rothengatter and Fuller speed control plays a significant role in driving behaviour because speed influences task conditions and hence the frequency of violations or errors also increases [9] [10]. As Figure 6 indicates, the driver was not able to control the car and drive on-road due to high speed driving. 


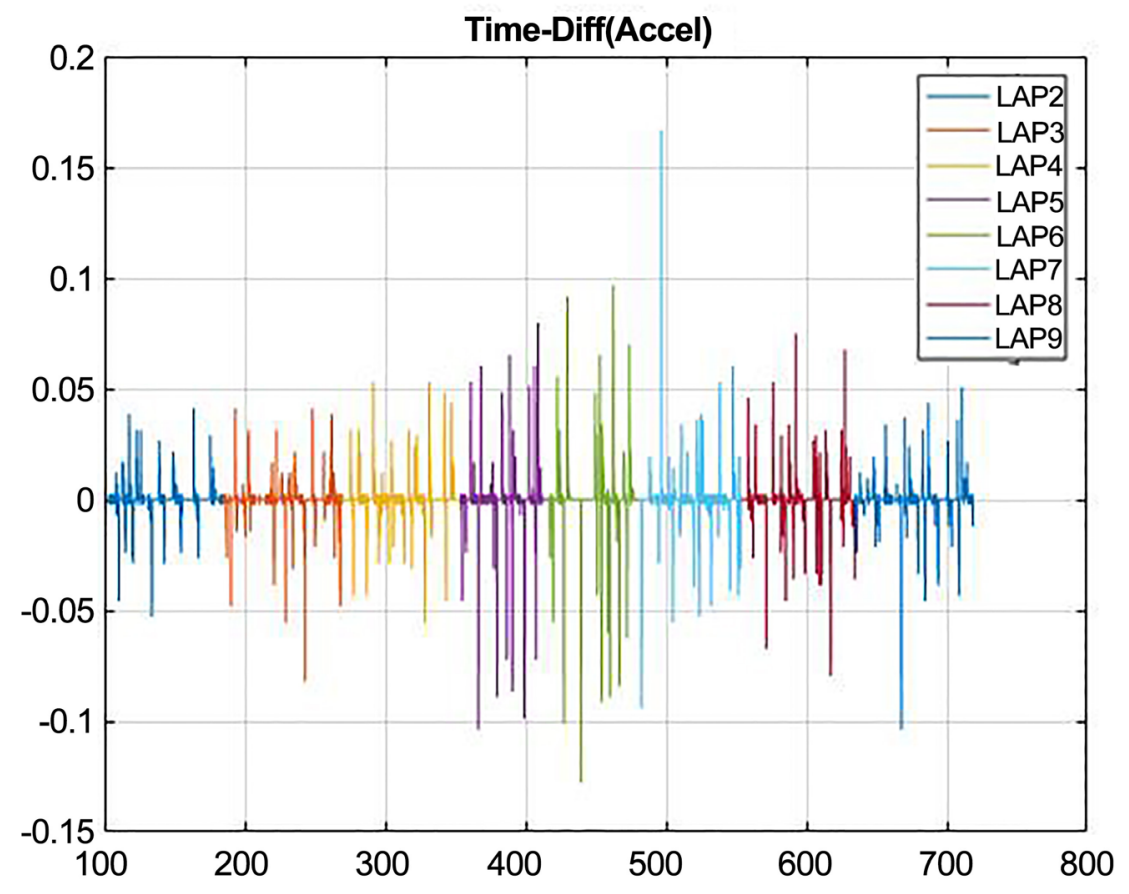

Figure 9. Acceleration data of each Lap.

A similar research shows that participants generally tend to increase their speed as well as the number of violations per time unit [11]. Participants reduced errors during forced-paced driving and increased speed during self-paced driving. Additionally, a positive correspondence is expected between violations and speed of the given tasks [11].

\section{Conclusions and Future Work}

In conclusion, the data of ten participants was gathered during this experiment, however, in this paper we analyzed one of the participant's performance data (Figure 1). The result of the experiment shows just how much driving fast can influence the performance of the driver. The result indicates that controlling the car, speed, tendencies and fatigue are all closely related. We will study more driver behavior and characteristics for future work. We will study and compare the results of the 9 other drivers to be able to understand more about driver difficulties and behavior. Using 3D virtual reality (HTC Vive) was extremely useful in simulating real world driving for the user, and after few Laps drivers adapted to the simulation/Virtual Reality (VR) world. The study result shows that an individual's behavior and characteristics such as maintaining the speed limit, remaining calm and relaxed when driving, driving at appropriate speeds depending on changes in road structures and etc. while driving can affect their performance in a simulated environment as we discussed in the data analysis section. This study was limited by a small sample size and one assessor was observing the participants and instructing them when questions or problems arose. The driving course in this study was limited to one scenario. Furthermore, future re- 
search should include more scenarios and different aspects of driver behavior such as mirror checking, speed at intersections, maintaining the speed limit, and obeying street laws can be implemented and analyzed in future studies.

For the future study we want to try to understand driver behavior and the influence of digital Mirror on behavior and performance. By using an eye tracker device (Tobii TX300), we can accurately analyze every instance of where the driver was looking while driving. It's so accurate that we can even observe the order of every glance the eye made and for how long. If a driver looks at objects in the car or at the side-view mirrors or the traffic, it can affect the driver's performance. We can analyze and compare the result with verity of scenarios and different locations of the side-view mirrors.

\section{References}

[1] Meuleners, L. and Fraser, M. (2015) A Validation Study of Driving Errors Using a Driving Simulator. Transportation Research Part F. Traffic Psychology and Behaviour, 29, 14-21.

http://www.sciencedirect.com/science/article/pii/S1369847814001764

[2] Shechtman, O., Classen, S., Awadzi, K. and Mann, W. (2009) Comparison of Driving Errors between On-the-Road and Simulated Driving Assessment: A Validation Study. Traffic Injury Prevention, 10, 379-385. https://doi.org/10.1080/15389580902894989

[3] Brooks, J.O., Goodenough, R.R., Crisler, M.C., Klein, N.D., Alley, R.L., Koon, B.L., et al. (2010) Simulator Sickness during Driving Simulation Studies. Accident Analysis and Prevention, 42, 788-796.

[4] Classen, S., Bewernitz, M. and Shechtman, O. (2011) Driving Simulator Sickness: An Evidence-Based Review of the Literature. American Journal of Occupational Therapy, 65, 179-188. https://doi.org/10.5014/ajot.2011.000802

[5] Lew, H.L., Poole, J.H., Lee, E.H., Jaffe, D.L., Huang, H.C. and Brodd, E. (2005) Predictive Validity of Driving-Simulator Assessments Following Traumatic Brain Injury: A Preliminary Study. Brain Injury, 19, 177-188. https://doi.org/10.1080/02699050400017171

[6] Smolensky, M.H., Di Milia, L., Ohayon, M.M. and Philip, P. (2011) Sleep Disorders, Medical Conditions, and Road Accident Risk. Accident Analysis and Prevention, 43, 533-548.

[7] Hofman, G.M., Summers, C.G., Ward, N., Bhargava, E., Rakauskas, M.E. and Holleschau, A.M. (2012) Use of a Driving Simulator to Assess Performance under Adverse Weather Conditions in Adults with Albinism. Perceptual and Motor Skills, 114, 679-692. https://doi.org/10.2466/13.24.27.PMS.114.2.679-692

[8] Fisher, D.L., Rizzo, M., Caird, J. and Lee, J.D. (2010) Handbook of Driving Simulation for Engineering, Medicine, and Psychology. Taylor \& Francis, Boca Raton.

[9] Rothengatter, T. (1997) Errors and Violations as Factors in Accident Causation. In: Rothengatter, T. and Carbonell Vaya, E., Eds., Traffic and Transport Psychology, Theory and Application, Pergamon, Amsterdam, 59-64.

[10] Fuller, R. (2005) Towards a General Theory of Driver Behaviour. Accident Analysis \& Prevention, 37, 461-472.

[11] De Winter, J.C.F., et al. (2007) Violations and Errors during Simulation-Based Driver Training. Ergonomics, 50, 138-158. https://doi.org/10.1080/00140130601032721 
Submit or recommend next manuscript to SCIRP and we will provide best service for you:

Accepting pre-submission inquiries through Email, Facebook, LinkedIn, Twitter, etc. A wide selection of journals (inclusive of 9 subjects, more than 200 journals)

Providing 24-hour high-quality service

User-friendly online submission system

Fair and swift peer-review system

Efficient typesetting and proofreading procedure

Display of the result of downloads and visits, as well as the number of cited articles Maximum dissemination of your research work

Submit your manuscript at: http://papersubmission.scirp.org/

Or contact jtts@scirp.org 